\title{
DESIGN AND FUEL ECONOMY OF A SERIES HYDRAULIC HYBRID VEHICLE
}

\author{
Peter ACHTEN*, Georges VAEL*, Mohamed Ibrahim SOKAR** and Torsten KOHMÄSCHER** \\ * Innas BV \\ Nikkelstr. 15, 4823AE Breda, the Netherlands \\ (E-mail: pachten@innas.com) \\ ** Institute for Fluid Power Drives and Controls (IFAS) \\ RWTH Aachen University \\ Steinbachstr. 53 B, 52074 Aachen, Germany
}

\begin{abstract}
A series hydraulic hybrid drive train for application in a passenger car is described. This 'Hydrid' drive train features an in-wheel hydraulic motor in all four wheels, hydraulic transformers for power control and hydraulic-pneumatic accumulators for energy storage and power management. The hydrostatic components are based on the highly efficient floating cup principle. The result is an efficient all-wheel drive vehicle with variable traction control on the front and rear axis. The fuel economy and the $\mathrm{CO}_{2}$-emission of the drive train are calculated for a mid-class sedan while driving the New European Driving Cycle (NEDC). The efficiency of the hydrostatic components is derived from efficiency measurements of the floating cup pump.
\end{abstract}

\section{KEY WORDS}

Series Hybrid Hydraulic Vehicle Efficiency

\section{NOMENCLATURE}

$b_{\text {NEDC }} \quad$ specific fuel consumption $[1 / 100 \mathrm{~km}]$

c conversion constant $[1 / 100 \mathrm{~km} / \mathrm{Wh}]$

$E_{d r a g}$ cumulative rolling and aerodynamic resistance during the NEDC [Wh]

$E_{k i n} \quad$ cumulative kinetic energy during the NEDC [Wh]

$\eta_{\text {ICE }} \quad$ average cycle efficiency of a diesel engine [-]

$\eta_{\text {recup }}$ degree of recuperated kinetic energy which is actually stored in the accumulator [-]

$\eta_{T} \quad$ average cycle efficiency of a transmission component of a series hybrid [-]

$\varphi$

rotational position of the motor shaft $\left[{ }^{\circ}\right]$

\section{INTRODUCTION}

The fuel consumption of passenger cars could be strongly reduced if the engine would always be operated around the best point, where the engine has the highest efficiency. According to Breitfeld from BMW [1] the fuel consumption would then even be halved. To achieve this:

- a series hybrid drive train must be introduced

- the engine has to be operated in start-stop-operation

- low load operation of the engine should be avoided

- $\quad$ energy storage is needed for power management and energy recuperation.

This paper describes the 'Hydrid' [2, 3, 4], a full hydrostatic hybrid transmission that could fulfil the require- 
ments for such a drive train. The IFAS-institute of RWTH Aachen University in Germany has determined the fuel consumption and $\mathrm{CO}_{2}$-emission of the Hydrid. Starting point for the study is that the hybrid vehicle has the same performance, size and weight as the original non-hybrid vehicle. The study is performed for a mid-sized sedan driving the New European Driving Cycle (NEDC). The results of this study are summarized in this paper.

\section{REQUIREMENTS FOR SERIES HYBRIDS}

Series hybrid drive trains have several advantages compared to parallel systems. In parallel systems, an extra transmission is added to the mechanical transmission, which increases both the weight and the cost of the vehicle. In a series hybrid system, the mechanical transmission can be completely eliminated and replaced by an electric or hydraulic system, which allows power management and energy storage. The engine is no longer connected to the wheels but can now be optimized for producing energy in the most optimal way.

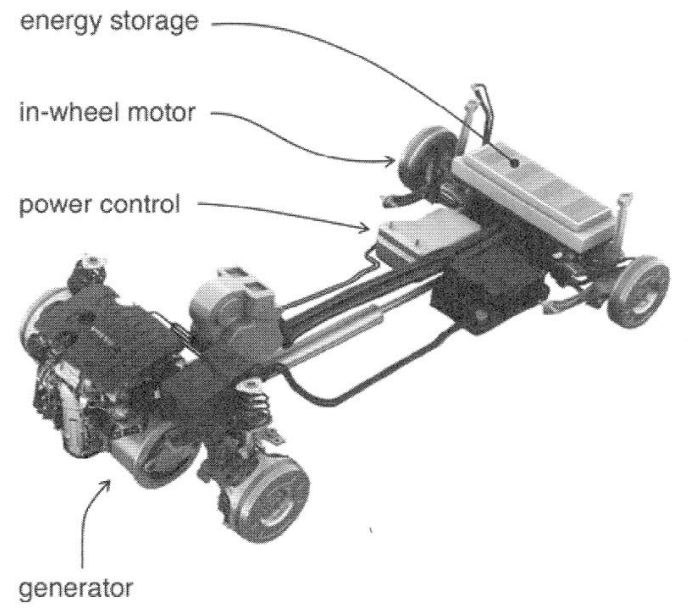

Figure 1: Transmission components of a series hybrid

This, however, is only an advantage if all transmission components (see figure 1) have a high efficiency, also at part load and low power operating points. If, for simplicity reasons, all the transmission components are assumed to have an equal average cycle efficiency $\eta_{T}$, then the specific fuel consumption can be calculated:

$$
b_{N E D C}=c \cdot \frac{E_{\text {drag }}+E_{k i n}\left(1-\eta_{T}^{6} \cdot \eta_{\text {recup }}\right)}{\eta_{I C E} \cdot \eta_{T}^{4}}
$$

in which:

$$
\begin{aligned}
& c=9.25 \cdot 10^{-4}\left[\frac{1}{100 \mathrm{~km}} \frac{1}{W h}\right] \\
& E_{\text {drag }}=633 \mathrm{Wh}
\end{aligned}
$$

$$
E_{\text {kin }}=397 \mathrm{Wh}
$$

The amount of rolling and aerodynamic resistance $\left(E_{\text {drag }}\right)$, and the amount of kinetic energy $\left(E_{\text {kin }}\right)$ are calculated for a mid-sized sedan, while driving the NEDC. Since the engine can always be operated in the area with highest efficiency, the average (diesel) engine efficiency can be assumed to be quite high:

$$
\eta_{\text {ICE }}=0.37
$$

The specific fuel consumption of the passenger car can now be calculated for various degrees of recuperation and various transmission component efficiencies:

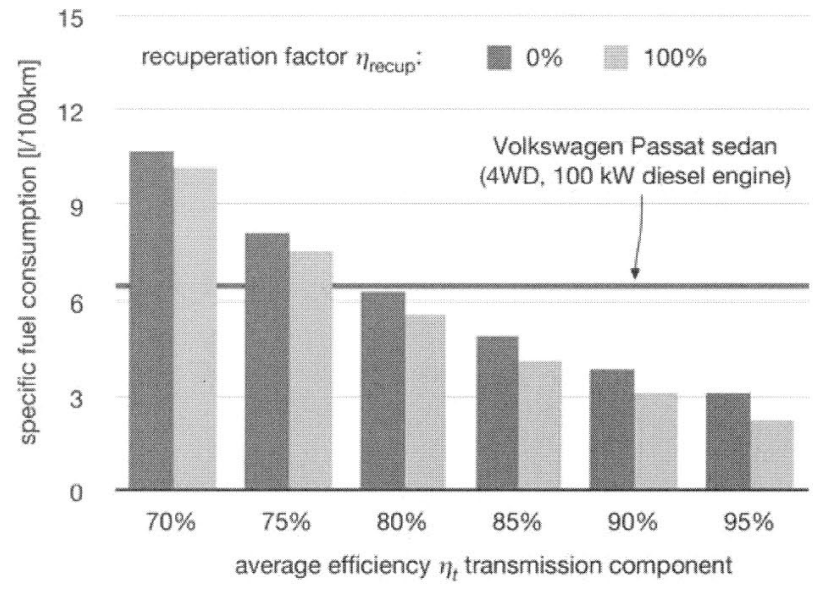

Figure 2: NEDC specific fuel consumption of a series hybrid vehicle, in comparison to the Volkswagen Passat benchmark.

This, rather simple analysis, shows the strong reduction of the specific fuel consumption that can be achieved with a series hybrid transmission. Compared to a vehicle with a conventional mechanical transmission, the fuel consumption can be reduced by more than $50 \%$. Energy recuperation has a modest effect on the fucl consumption: for the NEDC 0.5 to 0.9 litres per $100 \mathrm{~km}$. The specific fuel consumption is first and foremost affected by the efficiency of the transmission components. The average cycle efficiency of the individual components has to be higher than $80 \%$ in order to achieve a substantial improvement of the fuel economy.

This demand cannot be fulfilled with current electric components [5]. Furthermore the electric transmission will substantially increase the weight and the cost of the transmission if the vehicle performance is not to be compromised. 
The alternative for a series electric hybrid vehicle would be a full hydrostatic transmission, including hydraulic accumulators. Although accumulators have a rather low energy density, they are favoured for their high power density, much higher than of electric batteries. The torque control of the wheels can be realized by means of secondary controlled, variable displacement motors. As with the electric motors, the size of the hydraulic motors has to be chosen for maximum speed and maximum torque requirements. By reducing the swash-plate angle of the variable displacement motor, the torque to the wheels can be controlled. But this again results in a poor efficiency at low power demands, which are typical for average driving conditions, for instance as defined by the NEDC.

Another disadvantage of current variable displacement hydraulic motors is the reduced torque at start-up and low rotational speeds. This is for a part due to stick-slip friction. The start-up torque can further be reduced because of the strong torque variations caused by the limited number of pistons. The torque variation also creates concerns about the noise, vibration and harshness (NVH) of a hydrostatic drive train [6].

\section{NEW HYDROSTATIC COMPONENTS}

A series hydraulic hybrid transmission only makes sense, if all the transmission components have a high average cycle efficiency. Furthermore a solution for the $\mathrm{NVH}$-issue has to be found.

Two recently developed hydrostatic principles are introduced to fulfil these demands:

- the Floating Cup Principle

- $\quad$ and the Innas Hydraulic Transformer.

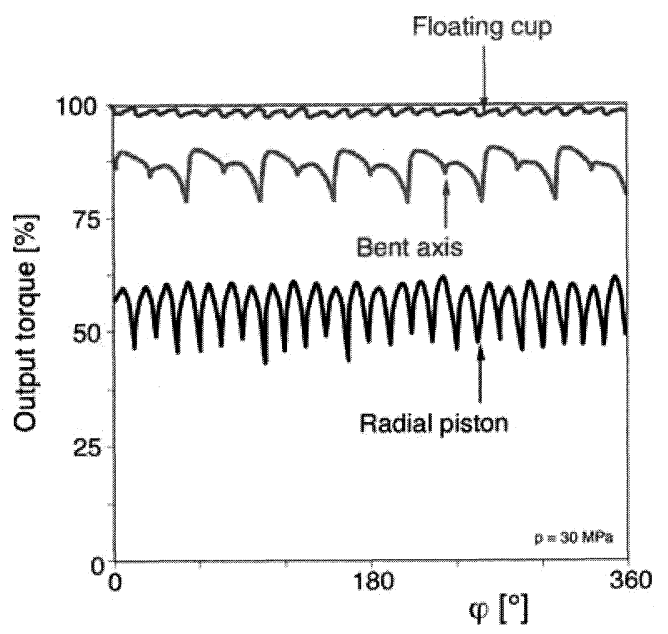

Figure 3: Low speed torque of three different hydraulic motors relative to the theoretical maximum torque
The Floating Cup Principle is a highly efficient positive displacement principle, which is developed for hydrostatic pumps, motors and transformers [7, 8]. Floating cup machines typically have around 24 pistons; 3 to 4 times as much as in conventional piston pumps and motors. This strongly reduces the noise, pulsation and vibration levels. Furthermore, the Floating Cup principle has extremely low friction losses. The effect of the low friction losses and the high number of pistons can be seen in the diagram of figure 3 which shows the torque output (relative to the maximum theoretical torque) measured at a low rotational speed $(<1 \mathrm{rpm})$ of a floating cup motor, compared to a bent axis and a radial piston motor.

The hydraulic transformer eliminates the need for variable displacement motors. Instead, each wheel will have its own constant displacement motor. The wheel torque is controlled by means of the hydraulic transformer, which controls the pressure level offered to the wheel motors, as well as the flow direction. The transformer is a continuously variable (hydraulic) transmission, converting the product of pressure and flow without any principle losses. The transformers can also act as pressure amplifiers, thereby creating a boost torque when needed.

\section{THE HYDRID}

On the basis of these new hydrostatic principles, a new series hydraulic hybrid, called the 'Hydrid', has been designed (figure 4). Each wheel has its own constant displacement motor. Due to the high power and torque density of the hydrostatic units, the increase of the unsprung wheel mass is limited. Alternatively, the hydraulic motors could be mounted on the chassis, driving the wheels by means of conventional constant-velocity joints. The motors act as pumps when braking, thereby recuperating the kinetic energy of the vehicle and storing it (as much as possible) in the high-pressure accumulator.

The backbone of the Hydrid is the Common Pressure Rail (CPR). This system collects and distributes all the power inside the vehicle. The accumulators determine the pressure levels in the system. On the high-pressure side, the pressure level varies between 200 and 400 bar.

The internal combustion engine delivers all its energy to a constant displacement pump. The torque demand of the pump is directly related to the pressure level in the high-pressure accumulator, and can consequently only vary between $50 \%$ (at 200 bar) and $100 \%$ (at 400 bar) of the maximum torque. Operation of the engine at low loads is therefore completely avoided. 


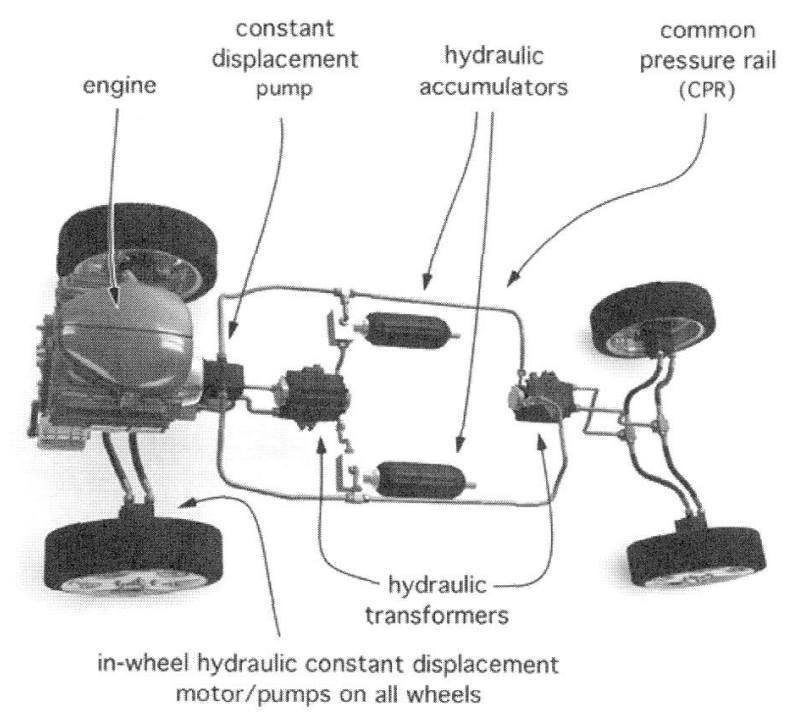

Figure 4: Main components of the Hydrid

Table 1: Hydraulic components:

The hydraulic transformers are the power converters of the transmission, and control the traction and the speed of the vehicle in four quadrants. There are two transformers, one for each axis. The system offers a variable traction control for the front and the rear axis. At low torque demand, one of the axes can be shut-off completely. The differential function is created by means of a simple hydraulic T-joint. With hydraulic valves, a differential lock, or even torque vectoring can be realized, much more simple and less expensive than with mechanical systems.

\section{MEASUREMENTS AND SIMULATIONS}

The Institute for Fluid Power Drives and Controls (IFAS) of the RWTH Aachen University has built a simulation model of the Hydrid in order to calculate the specific fuel consumption and the related $\mathrm{CO}_{2}$-emissions. For the pumps, motors and transformers, efficiency maps are used which are derived from recent efficiency measurements performed by IFAS on a $28 \mathrm{cc}$ constant displacement floating cup pump. For the engine, the efficiency map of a Mercedes Benz diesel motor was applied [9], having a peak efficiency of $40 \%$.

The size of the hydraulic components (see table 1) is chosen as such that the Hydrid has the same performance as the benchmark vehicle (a Volkswagen Passat sedan). Also the size (frontal area), aerodynamic resistance, rolling resistance, dynamic wheel diameter and vehicle weight have been chosen the same. Table 2 gives an overview of all the vehicle parameters. The test cycle used for the simulation was the NEDC specified by the European Community (directive 93/116/EC). According to this directive, some of the auxiliaries (like

\begin{aligned} & \hline Pump: $56 \mathrm{cc} / \mathrm{rev}$ constant displacement \\ & Accumulators: 20 litres (high- and low-pressure) \\ & Hydraulic transformers: $60 \mathrm{cc} / \mathrm{rev}$ (pump equivalent) \\ & Wheel motors: $45 \mathrm{cc} / \mathrm{rev}$ constant displacement \\ & \hline\end{aligned}

Table 2: Vehicle parameters

\begin{aligned} & \hline Vehicle: Volkswagen Passat all-wheel \\ & drive Sedan (2007 Germany) \\ & engine: $100 \mathrm{~kW}$ diesel engine \\ & maximum traction: $4400 \mathrm{~N} \\ &$ maximum vehicle speed: $190 \mathrm{~km} / \mathrm{h} \\ &$ empty curb weight: $1450 \mathrm{~kg} \\ &$ frontal area: $2,26 \mathrm{~m} 2 \\ &$ drag coefficient: 0,26 \\ & dynamic wheel diameter: $0,63 \mathrm{~m} \\ &$ rolling resistance \\ & coefficient: 0,008 \\ & \hline\end{aligned}

the compressor for the air-conditioning) do not have to be taken into account. It is assumed that the energy for the water pump, the cooling fan, the generator and the fuel injection system are included in the efficiency map of the diesel engine. It is furthermore assumed that the power steering in the Hydrid does not consume any energy during the NEDC. Having a CPR hydraulic system, the steering system can now be a closed circuit system with no power consumption while driving straight on (as is the case in the NEDC).

\section{FUEL CONSUMPTION}

The first results of the simulations were published at the 6th International Fluid Power Conference (6.IFK) in April 2008 [4]. In the IFK-paper, a double engine concept was assumed, having two $50 \mathrm{~kW}$ diesel engines. In this paper the simulation has been run with a single 100 $\mathrm{kW}$ engine. Furthermore, the air density was adjusted from 1,29 to $1,2 \mathrm{~kg} / \mathrm{m}^{3}$, which is the correct value for an air temperature of $20^{\circ} \mathrm{C}$.

Figure 5 shows the outcome of the simulation with respect to the fuel consumption. The result is compared to the fuel consumption and $\mathrm{CO}_{2}$-emission of a Volkswagen Passat sedan having an all-wheel drive manual transmission and a $100 \mathrm{~kW}$ diesel engine. The data for this benchmark are provided by Volkswagen Germany and are valid for the NEDC test cycle.

The Hydrid strongly reduces the specific fuel consumption, on average with $58 \%$. Contrary to conventional vehicles, driving in the city consumes less fuel (per km travelled) than driving on the highway. This is to be expected for any efficient drive train, since the aero- 
dynamic drag is much less while driving in the city. The high efficiency of the Hydrid is the result of:

- the high average cycle efficiency of the hydrostatic components;

- recuperation of the kinetic energy while braking;

- operation of the internal combustion engine close to the best point.

The size of the 20 litres high-pressure accumulator is sufficient for recuperating about $90 \%$ of the kinetic energy during the city part of the NEDC. During the entire NEDC $58 \%$ of the kinetic energy is recuperated. The rest is dissipated by means of a pressure relief valve, especially during the final brake action of the NEDC, which is a full stop from $120 \mathrm{~km} / \mathrm{h}$. Including the recuperated energy, the total average efficiency of the hydraulic transmission is $95 \%$. This is somewhat higher than the average cycle efficiency of the mechanical all-wheel drive transmission of the benchmark, which is estimated to be $91 \%$.

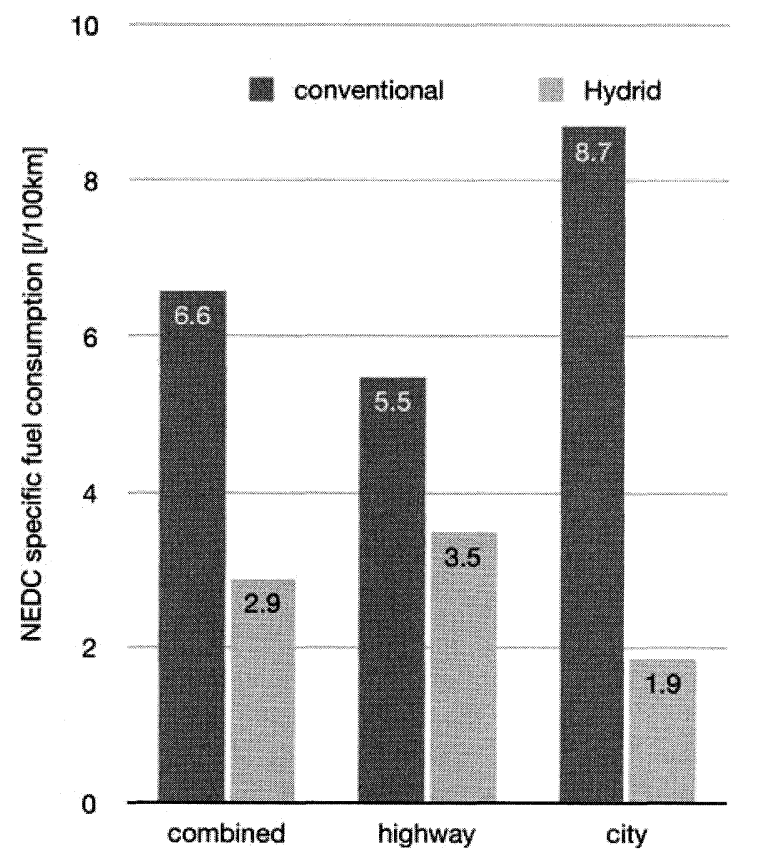

Figure 5: Specific fuel consumption for the Hydrid compared to the conventional benchmark (comparison based on a mid-sized 4 WD sedan with a $100 \mathrm{~kW}$ diesel engine, driving the NEDC)

The most important advantage of the Hydrid is that it allows the engine to run at high loads and hence at a high efficiency. Figure 6 shows a Pareto-distribution of the propulsion power required by the vehicle at the wheels. During $40 \%$ of the cycle time the wheels don't require any propulsion power; this is when the vehicle is standing still $(24 \%)$ or decelerating $(16 \%)$. The maximum required propulsion power is $32 \mathrm{~kW}$, which is much lower than the installed engine power. About $90 \%$ of the time the required wheel propulsion power is even below $11 \mathrm{~kW}$.

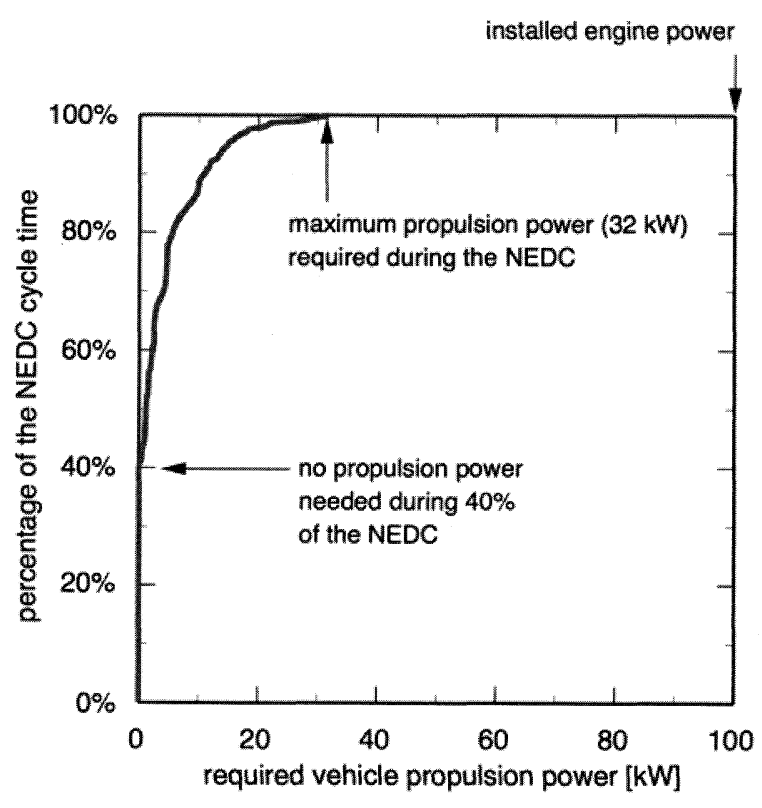

Figure 6: Pareto chart of the propulsion power required during the NEDC

In a conventional vehicle, there is no energy storage between the engine and the wheels. Consequently all the engine power has to be delivered directly to the wheels: the engine can't produce more mechanical power than the vehicle requires for propulsion. Since the engine can't be operated below a certain minimum speed, the engine has to be operated at low loads for the greater part of the cycle operation. Because the engine has a poor efficiency at these low load conditions (especially during city operation), the total drive train efficiency is strongly reduced and the specific fuel consumption is increased.

In the Hydrid, the engine is decoupled from the wheels. Instead the engine power is now completely converted to hydraulic power by means of a constant displacement pump. The pump delivers its pump flow to the highpressure accumulator, having a pressure range of 200 400 bar. Having a constant displacement of $56 \mathrm{cc} / \mathrm{rev}$, the pressure range of the accumulator requires a torque range of about 180 to $360 \mathrm{Nm}$. Consequently, the engine will only be operated between 50 and $100 \%$ load always having a nearly maximum efficiency.

\section{$\mathrm{CO}_{2}$-EMISSION}

The $\mathrm{CO}_{2}$-emission follows directly form the calculated specific fuel consumption. As before the $\mathrm{CO}_{2}$-emission from the Hydrid is compared to the NEDC-data for the benchmark vehicle (as provided by the car manufactu- 
rer).

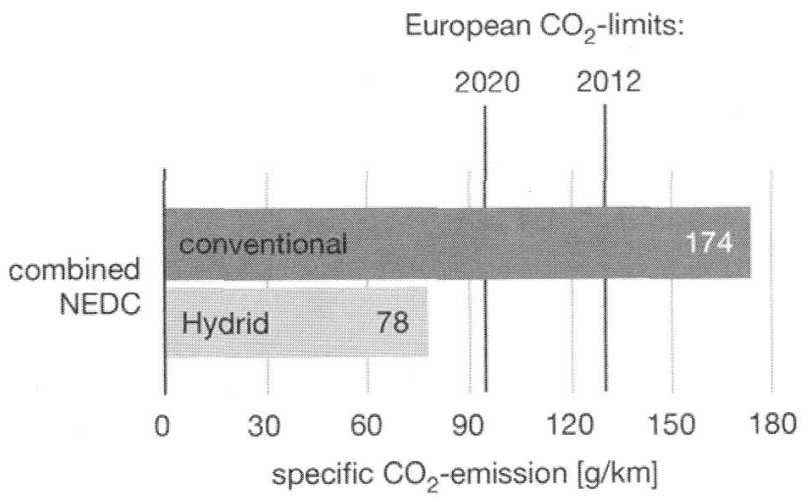

Figure 7: Specific $\mathrm{CO}_{2}$-emission for the Hydrid compared to the conventional benchmark and the $\mathrm{CO}_{2}$-emission limits expected for Europe (comparison based on a mid-sized 4WD sedan with a $100 \mathrm{~kW}$ diesel engine, driving the NEDC)

For the conventional vehicle, the specific $\mathrm{CO}_{2}$-emission is $174 \mathrm{gr} / \mathrm{km}$. This is much higher than the limits set by the European Community. The EU has agreed that by the year 2012, the average $\mathrm{CO}_{2}$-emissions from new passenger cars should not exceed $130 \mathrm{~g} \mathrm{CO}_{2}$ per $\mathrm{km}$. By 2020 , the limit is expected to be further reduced to 95 grammes $\mathrm{CO}_{2}$ per $\mathrm{km}$. Both limits can easily be met with the Hydrid.

\section{ELECTRIC SYSTEM INTEGRATION}

In the Hydrid, the hydraulic transmission competes with the mechanical transmission (which it eventually completely replaces), but it doesn't exclude electric systems and electric batteries.

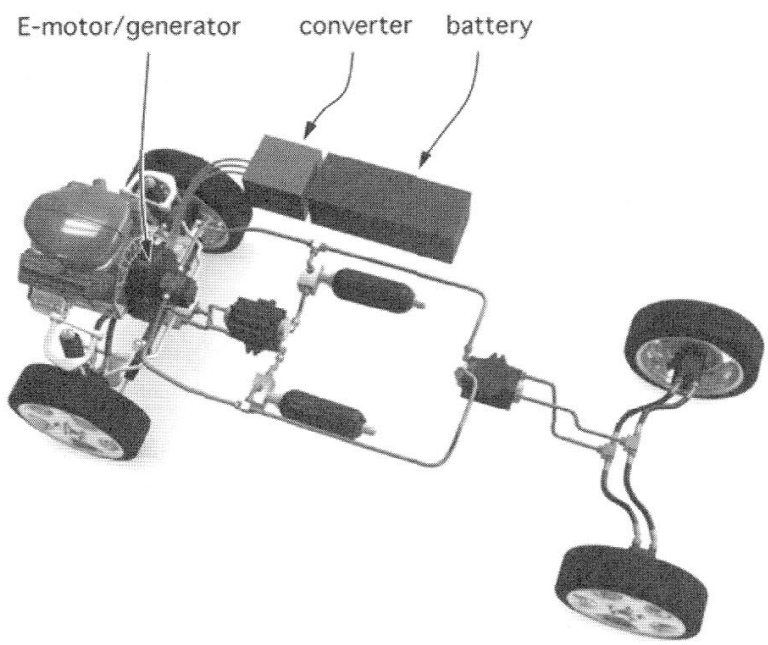

Figure 8: Electric system integration
On the contrary: the high power density of the accumulators can be very well combined with the high energy capacity of the batteries (figure 8). The hydraulic transmission handles all the power transients and peaks. Therefore, the electric system only needs to be designed for a base load of 5 to $10 \%$ of the installed engine power.

\section{CONCLUSION}

The fuel consumption and related $\mathrm{CO}_{2}$-emissions of passenger cars can be strongly reduced by means of a series hybrid transmission. Series hybrid systems are however only successful if the individual transmission components are extremely efficient. This study has proven that the new floating cup principle and the hydraulic transformer fulfil this requirement. The specific fuel consumption can be reduced by more than $50 \%$, without compromising the performance, size or weight of the vehicle.

\section{REFERENCES}

1. Breitfeld, C.(2007) The Efficiency-Optimised Drive - a Vision? Proc. $6^{\text {th }}$ Int. CTI Symposium, Berlin

2. Achten, P.A.J. (2007) Changing the paradigm, Proc. of the 10th Scandinavian International Conference on Fluid Power (SICFP'07), May 21-23, 2007, Tampere Finland

3. Achten, P.A.J. (2007) The Hydrid transmission, Proc. SAE 2007 Commercial Vehicle Engineering Congress \& Exhibition, October 2007, Rosemont USA, SAE 2007-01-4152

4. Achten, P.A.J. et al (2008) Energy efficiency of the Hydrid, Proc. Int. Fluid Power Conference 6.IFK, Dresden, Germany

5. Abthoff, J, et al (1998) The Mercedes-Benz C-class series hybrid, Proc. SAE Int. Congress and exhibition, 1998, SAE-paper 981123

6. Elahlnla, M.H. et al (2006) Noise and vibration control in hydraulic hybrid vehicles, SAE automotive dynamics, stability \& controls conf. and exhibition 2006, SAE-paper 2006-01-1970

7. Achten, P.A.J. et al (2003) Design and testing of an axial piston pump based on the floating cup principle, Proc. of the 8th Scandinavian International Conference on Fluid Power, SICFP'03, Tampere, Finland, May 7-9, 2003

8. 20. Achten, P.A.J. (2003) Designing the impossible pump, Proc. Hydraulikdagarna 2003, Linköping, Sweden, June 3-4, 2003

9. Digeser, S. et al (2005) Der neue Dreizylinder-Dieselmotor von Mercedes-Benz fur Smart und Mitsubishi, MTZ 1/2005 Vol. 66 